\title{
Glucocorticoid receptor antagonism reverts docetaxel resistance in human prostate cancer
}

\author{
Jan Kroon ${ }^{1,2}$, Martin Puhr ${ }^{3}$, Jeroen T Buijs' ${ }^{1}$, Geertje van der Horst ${ }^{1}$, Daniëlle M Hemmer ${ }^{1}$, \\ Koen A Marijt ${ }^{4}$, Ming S Hwang ${ }^{5}$, Motasim Masood ${ }^{5}$, Stefan Grimm ${ }^{5}$, Gert Storm ${ }^{2,6}$, \\ Josbert M Metselaar ${ }^{2}$, Onno C Meijer ${ }^{7}$, Zoran Culig ${ }^{3}$ and Gabri van der Pluijm ${ }^{1}$ \\ ${ }^{1}$ Department of Urology, Leiden University Medical Center, Albinusdreef 2, 2333 ZA Leiden, The Netherlands \\ ${ }^{2}$ Department of Targeted Therapeutics, MIRA Institute for Biological Technology and Technical Medicine, \\ University of Twente, Enschede, The Netherlands \\ ${ }^{3}$ Department of Urology, Medical University of Innsbruck, Innsbruck, Austria \\ ${ }^{4}$ Department of Clinical Oncology, Leiden University Medical Center, Leiden, The Netherlands \\ ${ }^{5}$ Division of Experimental Medicine, Imperial College London, London, UK \\ ${ }^{6}$ Department of Pharmaceutics, Utrecht Institute for Pharmaceutical Sciences, Utrecht University, Utrecht, \\ The Netherlands \\ ${ }^{7}$ Department of Endocrinology, Leiden University Medical Center, Leiden, The Netherlands
}

Correspondence should be addressed to $G$ van der Pluijm Email

G.van_der_Pluijm@lumc.nl

\begin{abstract}
Resistance to docetaxel is a major clinical problem in advanced prostate cancer (PCa). Although glucocorticoids (GCs) are frequently used in combination with docetaxel, it is unclear to what extent GCs and their receptor, the glucocorticoid receptor (GR), contribute to the chemotherapy resistance. In this study, we aim to elucidate the role of the GR in docetaxel-resistant PCa in order to improve the current PCa therapies. GR expression was analyzed in a tissue microarray of primary PCa specimens from chemonaive and docetaxeltreated patients, and in cultured PCa cell lines with an acquired docetaxel resistance (PC3-DR, DU145-DR, and 22Rv1-DR). We found a robust overexpression of the GR in primary PCa from docetaxel-treated patients and enhanced GR levels in cultured docetaxel-resistant human PCa cells, indicating a key role of the GR in docetaxel resistance. The capability of the GR antagonists (RU-486 and cyproterone acetate) to revert docetaxel resistance was investigated and revealed significant resensitization of docetaxel-resistant PCa cells for docetaxel treatment in a dose- and time-dependent manner, in which a complete restoration of docetaxel sensitivity was achieved in both androgen receptor (AR)-negative and AR-positive cell lines. Mechanistically, we demonstrated down-regulation of $\mathrm{BCl}-\mathrm{xL}$ and $\mathrm{BCl}-2$ upon GR antagonism, thereby defining potential treatment targets. In conclusion, we describe the involvement of the GR in the acquisition of docetaxel resistance in human PCa. Therapeutic targeting of the GR effectively resensitizes docetaxel-resistant PCa cells. These findings warrant further investigation of the clinical utility of the GR antagonists in the management of patients with advanced and docetaxel-resistant PCa.
\end{abstract}

\author{
Key Words \\ - docetaxel \\ - glucocorticoid receptor \\ - prostate cancer \\ - therapy resistance
}

Endocrine-Related Cancer (2016) 23, 35-45 Printed in Great Britain

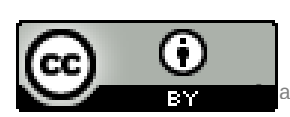

This work is licensed under a Creative Commons Attribution 3.0 Unported License. 


\section{Introduction}

Resistance to chemotherapy is a major hurdle in prostate cancer (PCa) treatment. Although chemotherapeutic treatments typically display initial benefit, cancer cells frequently acquire novel characteristics that will render these cells unresponsive to current cytotoxic treatments. Docetaxel (Taxotere, Sanofi-Aventis, Paris, France) is a microtubule-stabilizing agent that is clinically approved for a range of malignancies, including castrationresistant PCa (CRPC) for which it is the standard-of-care and prolongs survival of patients (Tannock et al. 2004). Unfortunately, tumors inevitably progress due to the acquired docetaxel resistance ( $\mathrm{O}^{\prime} \mathrm{Neill}$ et al. 2011). In addition, docetaxel resistance is often accompanied with a cross-resistance, i.e., dampened efficacy of other antitumor therapeutics and conversely, the use of other therapeutic agents, e.g., antiandrogens, appears to be associated with the emergence of resistance to docetaxel (van Soest et al. 2014). Therefore, identification of the underlying molecular mechanisms of docetaxel resistance is of a pivotal importance to combat docetaxel resistance in clinics (Madan et al. 2011).

The glucocorticoid receptor (GR) is a receptor that, upon binding of glucocorticoids (GCs) (e.g. dexamethasone (DEX)), regulates gene expression. GC binding to the GR leads to a rapid GR dimerization and subsequent nuclear translocation where it interacts with the GC response elements or transcription factors (Lewis-Tuffin $\&$ Cidlowski 2006). Although GCs are frequently administered to patients with advanced $\mathrm{PCa}$, mainly for antiemetic purposes, their usage remains controversial as both pro- and antitumor effects have been described (Montgomery et al. 2014). On the one hand, direct antitumor efficacy of DEX has been described in preclinical (Kroon et al. 2015) and clinical studies (Venkitaraman et al. 2008). On the other hand, GC usage seems to be associated with the resistance to antiandrogen therapy (Arora et al. 2013, Isikbay et al. 2014) and chemotherapy (Zhang et al. 2007). Simultaneous DEX administration was shown to undermine the antitumor effects of paclitaxel in vitro and in vivo, thus giving rise to chemotherapy resistance (Zhang et al. 2007). Our hypothesis holds that GR antagonism may lead to the reversal of chemotherapy resistance. In this study we describe that elevated GR expression can mediate chemotherapy resistance, and that interference with the canonical GR signaling counteracts docetaxel resistance in PCa, thus resensitizing PCa cells for this chemotherapeutic agent.

\section{Materials and methods}

\section{Tissue microarray and immunohistochemistry}

To examine GR expression in docetaxel-treated PCa tissue specimens, we used a tissue microarray (TMA) of formalinfixed, paraffin-embedded tissue blocks of 14 PCa patients who underwent neoadjuvant chemotherapy with docetaxel before radical prostatectomy and of 14 untreated PCa patients (Puhr et al. 2012, 2014). Every patient is represented with three cancer and three benign cores on the TMA. The use of archived material was approved by the Ethics Committee of the Medical University of Innsbruck (study no. AM 3174 including amendment 2). Patients received no other chemotherapeutics or antiandrogens prior to the radical prostatectomy, and both groups were matched for Gleason score and age. Patient characteristics, TMA assembling, and staining protocols were performed as previously described (Puhr etal. 2012). The TMA was stained with anti-GR (1:200, D6H2L, Cell Signaling Technology Inc, Danvers, MA, USA).

Immunohistochemistry was performed with a Discovery - XT staining device (Ventana, Tucson, AZ, USA) and images were captured with a Zeiss Imager Z2 microscope (Zeiss, Vienna, Austria) equipped with Pixelink PL-B622-CU camera (Canimpex Enterprises Ltd, Halifax, NS, Canada). The scoring of the GR expression was performed as follows: the cores were scored for GR intensity (no signal (0), weak signal (1), moderate signal (2), and strong signal (3)) and the percentage of positive cells (0\% (0), 0-25\% (1), 25-50\% (2), 50-75\% (3), and over $75 \%(4))$. The immune reactivity score was calculated with the following formula: intensity score * positive cell score and the average of three cores per patient is depicted. Statistical differences between both groups were calculated with the Mann-Whitney $U$ test.

\section{Cell culture and reagents}

PC3, DU145, and 22Rv1 cells were cultured in RPMI-1640 supplemented with FCS, penicillin/streptomycin, and glutamine. Docetaxel-resistant cells (PC3-DR, DU145-DR, and 22Rv1-DR) were generated by increasing exposure to docetaxel and subsequently cultured under the presence of $12.5 \mathrm{nM}$ docetaxel (O'Neill et al. 2011, Puhr et al. 2012). The identity of cell lines was confirmed by short tandem repeat analysis and cell line passages used in all experiments ranged from p2 to p17. Docetaxel, RU-486 (mifepristone), verapamil (all Sigma-Aldrich), and ABT-263 (Selleckchem, Huissen, The Netherlands) were dissolved in EtOH, DEX (Buma,

Published by Bioscientifica Ltd 
Uitgeest, The Netherlands) in PBS and cyproterone acetate (CPA, Sigma-Aldrich) in $\mathrm{MeOH}$.

\section{CRISPR/CAS9}

sgRNA sequences (sgRNA_GR1: ACGGCTGGTCGACCTATTG) were designed using the CRISPR Design Tool (http://crispr.mit.edu) to specifically target exon 2 of the GR-1 gene and were cloned into a PCR expression vector (Addgene: 41824). PC3-DR were transfected with CAS9 WT (Addgene: 41815$)$ and sgRNA-GR1 plasmid ( $2 \mu \mathrm{g} /$ plasmid) using Fugene (Promega). The sensitivity to docetaxel was assessed in transiently transfected cells and in stable cell lines, generated by expansion of single cells. Knockdown efficiency was determined using western blot.

\section{Real-time qPCR}

Cells were incubated with DEX in combination with RU-486 or CPA for $6 \mathrm{~h}$ and mRNA was isolated using Tripure (Invitrogen). cDNA was synthesized by RT (Promega). Realtime qPCR was performed on the Bio-Rad IQ5 Cycler and gene expression was normalized to the expression of GAPDH. The primer sequences are: GAPDH, F: 5'-GACAGTCAGCCGCATCTTC- ${ }^{\prime}$; GAPDH, R: 5'-GCAACAATATCCACTTTACCAGAG-3'; GILZ. F: 5'-GCACAATTTCTCCATCTCCTTCTT-3'; GILZ, R: 5'-TCAGATGATTCTTCACCAGATCCA-3'; FKBP5, F: 5'-GAATGGTGAGGAAACGCCGAT-3'; FKBP5, R: 5'-TGCCAAGACTAAAGACAAATGGT- ${ }^{\prime}$; and P-glycoprotein (P-gp), F: 5'-CCCATCATTGCAATAGCAGG-3'; P-gp, R: 5'-GTTAAACTTCTGCTCCTGA-3'.

\section{Western blot}

Cells were lysed in RIPA buffer and protein was loaded on a SDS-PAGE gel and subsequently transferred to a nitrocellulose membrane. Membranes were incubated with the primary antibody overnight at $4{ }^{\circ} \mathrm{C}$ and with the secondary antibody for $1 \mathrm{~h}$ at room temperature. The following antibodies were used: anti-GR (1:500, sc-8992, Santa Cruz Biotechnology, Santa Cruz, CA, USA), antiGAPDH (1:10 000, Chemicon, Temecula, CA, USA), anti- $\beta$ actin (1:5000, Sigma), anti-Bcl-xL (1:1000, sc-23958, Santa Cruz Biotechnology), and anti-Bcl-2 (1:1000, sc-7382, Santa Cruz Biotechnology).

\section{Viability assay and clonogenic assay}

For the viability assay, cells were seeded 1500 cells/well and were exposed to docetaxel in combination with
RU-486 and/or CPA. Cell viability was measured using the MTS assay (Celltiter 96 Aqueous One Solution Cell Proliferation Assay; Promega). For the clonogenic assay, cells were seeded 100 cells/well and exposed to a combination of docetaxel and RU-486. After 10-14 days, wells were fixed with $4 \%$ paraformaldehyde, and colonies were stained using crystal violet.

\section{Cell death analysis}

Cell death was assessed using an Annexin V/propidium iodine (PI) assay (Invitrogen). PC3-DR or DU145-DR cells were seeded 200 000/well and treated with a combination of $30 \mathrm{nM}$ docetaxel and $3 \mu \mathrm{M}$ RU-486. Floating and adherent cells were harvested and incubated with FITCAnnexin $\mathrm{V}$ and PI before analysis with flow cytometry. Viable cells were defined as Annexin $\mathrm{V}^{-} / \mathrm{PI}^{-}$, early apoptotic cells as Annexin $\mathrm{V}^{+} / \mathrm{PI}^{-}$and late apoptotic/ necrotic cells as Annexin $\mathrm{V}^{+} / \mathrm{PI}^{+}$.

\section{Side population}

The drug efflux properties of cells were determined as previously described (Golebiewska et al. 2011). In short, cells were incubated with $3 \mu \mathrm{M}$ RU-486, $10 \mu \mathrm{M}$ CPA, or 0.05-5.0 $\mu \mathrm{M}$ P-gp inhibitor verapamil prior to addition of Hoechst $33342(5 \mu \mathrm{g} / \mathrm{ml}$, Sigma-Aldrich). To-Pro-3 $(0.5 \mu \mathrm{M}$, Life Technologies) was added to exclude dead cells. Hoechst 33342 exclusion was measured with the LSRII using $450 \mathrm{~nm}$ (Hoechst blue) and $675 \mathrm{~nm}$ (Hoechst red) filters after excitation with a $350 \mathrm{~nm}$ u.v. light.

\section{Statistical analysis}

All experimental data are presented as the mean +s.E.M. and represent three independent experiments. Significance was calculated using GraphPad Prism 5.0 Software (San Diego, CA, USA) using either t-test or two-way ANOVA with Bonferroni's post testing.

\section{Results}

GR expression is enhanced in prostate tumors of docetaxel-treated patients and functionally involved in docetaxel resistance in vitro

In this study, we aim to elucidate the role of the GR in docetaxel resistance. To this end, a TMA of 14 docetaxeltreated patients and 14 chemonaive patients was evaluated. Immunohistochemical analysis revealed a significant

Published by Bioscientifica Ltd. 
A
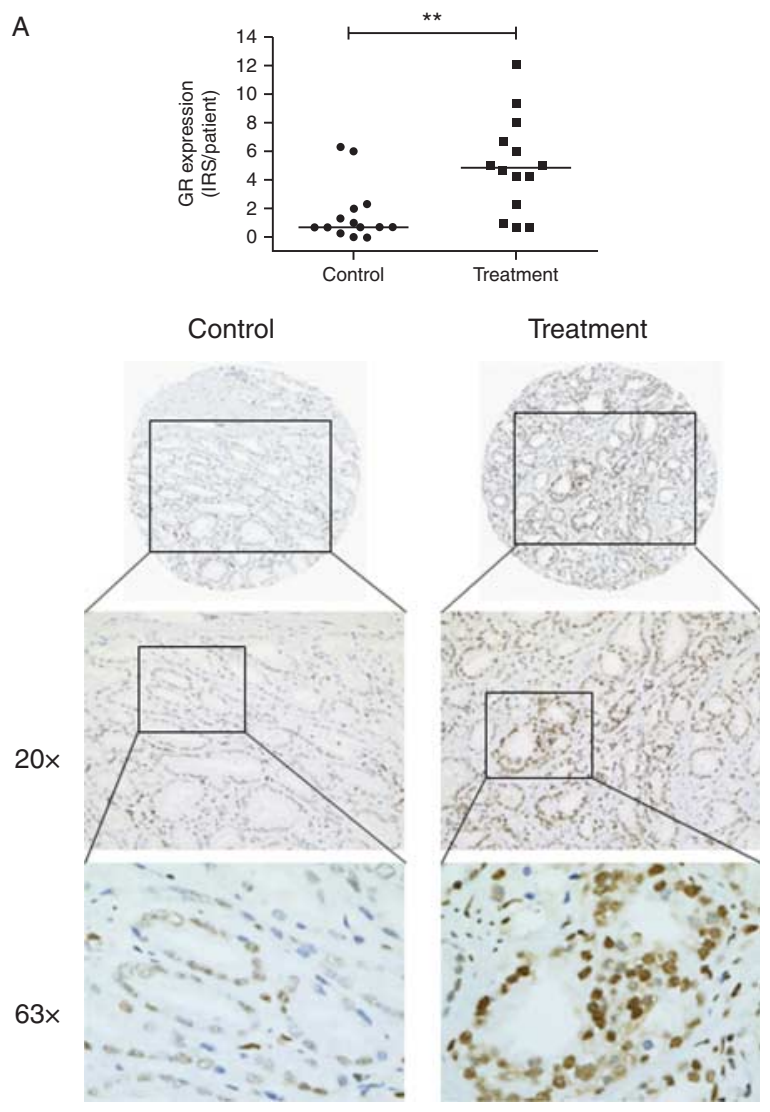

B
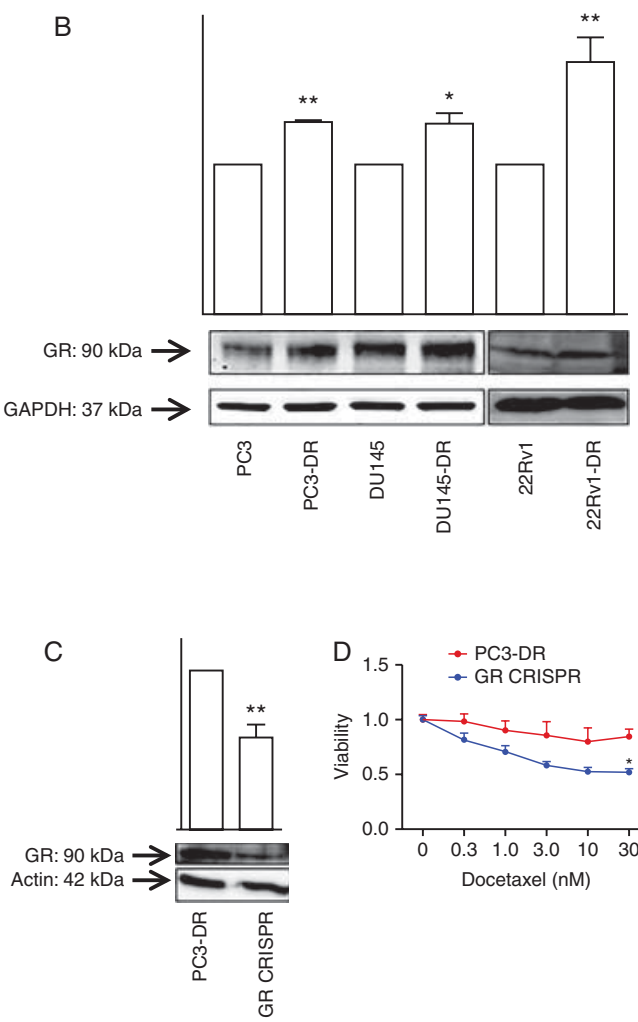

$D_{1.5} \rightarrow$ PC3-DR

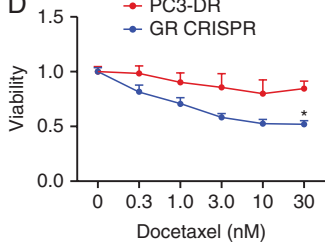

Figure 1

Glucocorticoid receptor (GR) expression is enhanced in docetaxel-treated patients and docetaxel-resistant cell lines and is functionally involved in chemotherapy resistance. (A) Tissue microarray (TMA) analysis revealed the GR overexpression in prostate cancer ( $P C a$ ) patient tissues treated with neoadjuvant docetaxel compared with chemonaive patients. $* * P<0.01$. (B) Protein expression analysis revealed that GR is overexpressed in

upregulation of the GR in PCa cells of docetaxel-treated patients compared with the chemonaive patients $(P<0.01$; Fig. 1A). In addition, docetaxel-resistant cell lines PC3-DR, DU145-DR, and 22Rv1-DR, largely unresponsive to docetaxel concentrations of up to $30 \mathrm{nM}$ (independent of serum GC; Supplementary Figure 1, see section on supplementary data given at the end of this article), displayed elevated expression of the GR protein levels when compared with their chemonaive counterparts (Fig. 1B). To evaluate the functional involvement of the GR in docetaxel resistance, we employed the CRISPR/CAS9-mediated knockout technology. Transient transfection of PC3-DR cells with GR-1-targeted sgRNA resulted in reduced GR expression (Fig. 1C) and, strikingly, enhanced sensitivity to docetaxel ( $-39 \%$ viability in PC3DR CRISPR GR compared with PC3-DR wt upon treatment with $30 \mathrm{nM}$ docetaxel, $P<0.05$; Fig. 1D). In addition, in docetaxel-resistant cell lines PC3-DR, DU145-DR, and 22Rv1-DR compared with their parental counterparts. ${ }^{\star} P<0.05$ vs parental and $* * P<0.01$ vs parental. (C) Transient CRISPR/CAS9-directed deletion of the GR-1 results in reduced GR expression. ${ }^{*} P<0.01$ vs PC3-DR. (D) Enhanced docetaxel sensitivity in PC3-DR GR CRISPR cells. ${ }^{*} P<0.05$ vs PC3-DR.

PC3-DR cells with stable GR knockout (Supplementary Figure 2A), that exhibit similar basal growth rates (Supplementary Figure 2B), docetaxel displays enhanced antitumor efficacy compared with PC3-DR wt cells (Supplementary Figure 2C).

\section{Therapeutic targeting of the GR completely} antagonizes DEX-induced transcriptional activity and strongly resensitizes docetaxel-resistant cells to docetaxel treatment

The induction of the GR signaling upon exposure with GR agonist DEX was examined by expression analysis of the GR-target genes GR-induced leucine zipper (GILZ) and FK506 binding protein 5 (FKBP5). DEX effectively induced GILZ and FKBP5 expression which was fully reversed by co-incubation with RU-486 (3 $\mu \mathrm{M})$ and CPA (10 $\mu \mathrm{M})$ (Fig. 2),

Published by Bioscientifica Ltd 

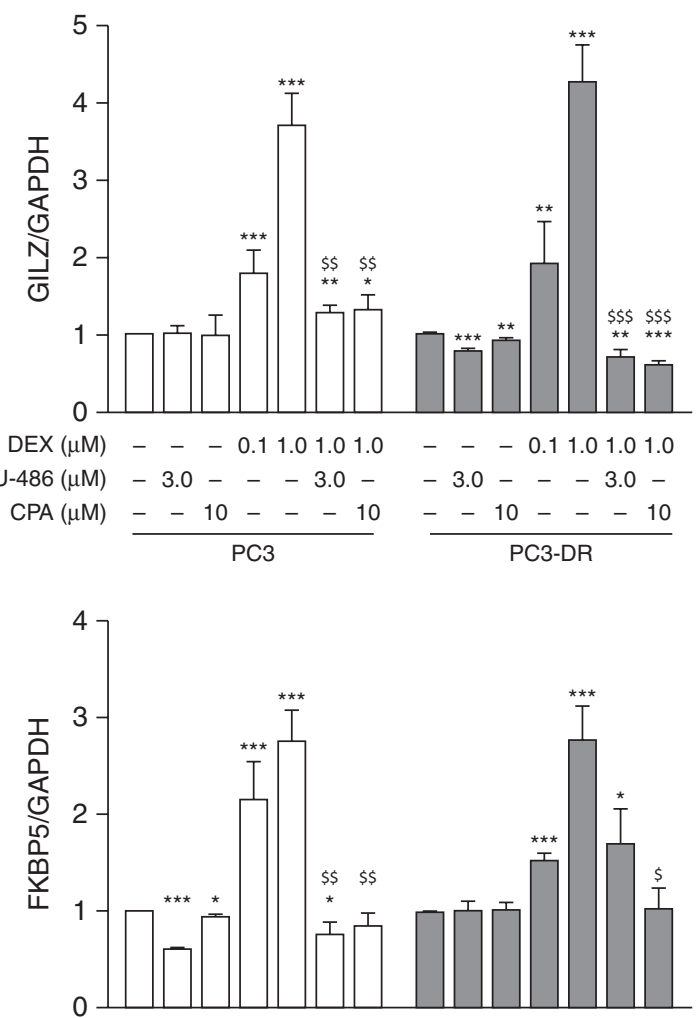

$\operatorname{DEX}(\mu \mathrm{M})-\quad-0.11 .01 .01 .0 \quad-\quad-0.11 .01 .01 .0$

$\mathrm{RU}-486(\mu \mathrm{M})$ - $3.0-\quad-3.0-\quad 3.0-\quad-3.0-$

$\mathrm{CPA}(\mu \mathrm{M}) \frac{--10--10}{\mathrm{PC} 3} \frac{-10---10}{\mathrm{PC3}}$

Figure 2

Dexamethasone (DEX)-induced transcriptional activity of the GR-target genes GILZ and FKBP5 is inhibited by RU-486 and CPA. Expression of the GR-target genes GILZ and FKBP5 in PC3-(DR) and DU145-(DR) cells upon

indicating of a complete blockage of the GR-activity by the GR-antagonists. To examine if modulation of the GRactivity affects sensitivity to docetaxel, docetaxel-resistant cell lines were incubated with GR-antagonists RU-486 or CPA. Exposure to RU-486 or CPA alone did not influence cell viability of parental (PC3 and DU145) and docetaxelresistant cell lines (PC3-DR and DU145-DR) (Supplementary Figure $3 \mathrm{~A}$, see section on supplementary data given at the end of this article). Strikingly, incubation with both GR-antagonists strongly sensitized docetaxelresistant cells to docetaxel treatment at doses $0.3-3 \mu \mathrm{M}$ for RU-486 and 3-10 $\mu \mathrm{M}$ for CPA (Fig. 3A). For further experiments, the doses $3 \mu \mathrm{M}$ RU-486 and $10 \mu \mathrm{M}$ CPA were chosen as these showed a strong reduction in cell viability of PC3-DR cells (80 and 70\% respectively) upon treatment with $30 \mathrm{nM}$ docetaxel $(P<0.001)$ (Fig. 3A). Antagonizing GR-mediated signaling activity significantly resensitized docetaxel-resistant cells to docetaxel
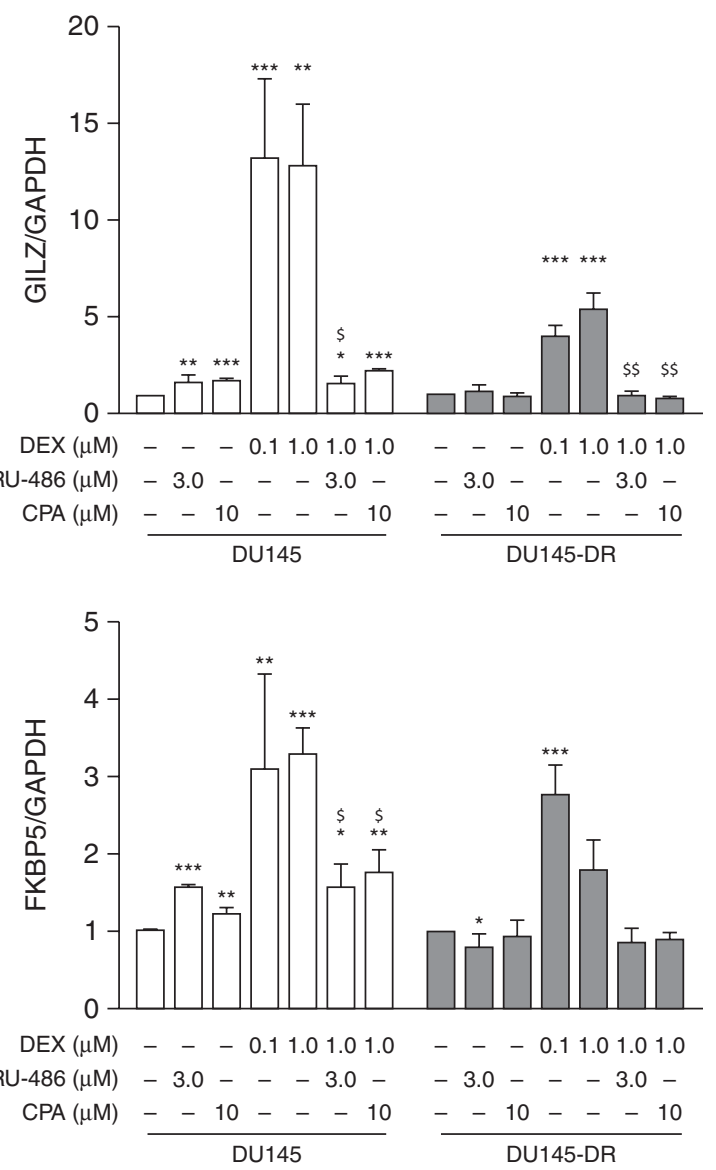

treatment with DEX and/or RU-486 or CPA. ${ }^{\star} P<0.05$ vs vehicle; $* * P<0.01$ vs vehicle; $* * * P<0.001$ vs vehicle; ${ }^{\$} P<0.05$ vs $1.0 \mu \mathrm{M} \mathrm{DEX} ;{ }^{\$} P<0.01$ vs $1.0 \mu \mathrm{M}$ DEX; and ${ }^{\$ \$} P<0.01$ vs $1.0 \mu \mathrm{M}$ DEX.

treatment dose-dependently (Fig. 3B) and in a timedependent fashion $(P<0.001$ at $48-72 \mathrm{~h})$ (Fig. 3C) while no effect was observed in docetaxel-sensitive tumor cells (Fig. 3B). In concordance with these findings, combined treatment with RU-486 and docetaxel largely diminished the clonogenic potential of both docetaxel-resistant cell lines (Supplementary Figure 3C). As PCa is fundamentally androgen receptor (AR) driven, we performed similar studies in AR-positive docetaxel-resistant cells. To this end, we utilized the 22Rv1 lineage, which expresses both full length AR as well as splice variant AR-V7 (Shiota et al. 2014). In concordance with our results in AR-negative cell lines, 22Rv1-DR cells are also resensitized to docetaxel upon RU-486 and CPA treatment in a dose-dependent (Fig. 3D) and time-dependent manner (Fig. 3E). These observations support a general role of the GR in the development of docetaxel resistance independently of AR status.

Published by Bioscientifica Ltd. 


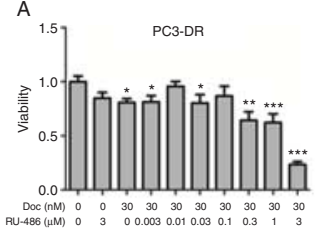

B

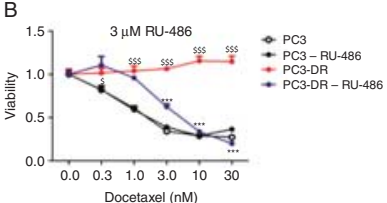
Docetaxel (nM)
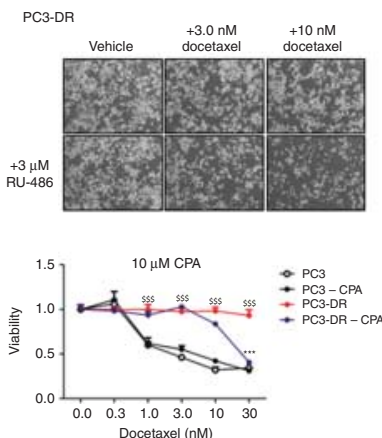
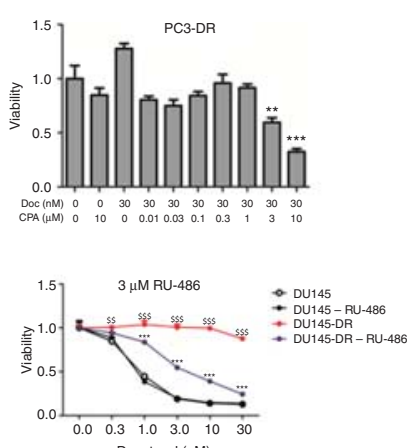
Docetaxel (nM)
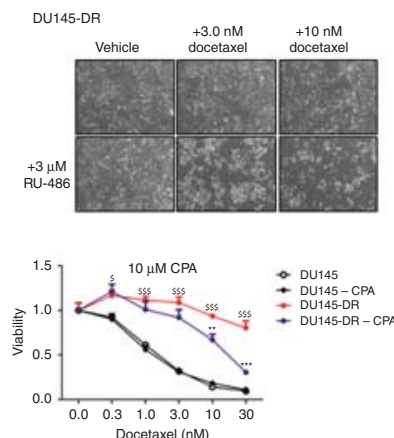

C
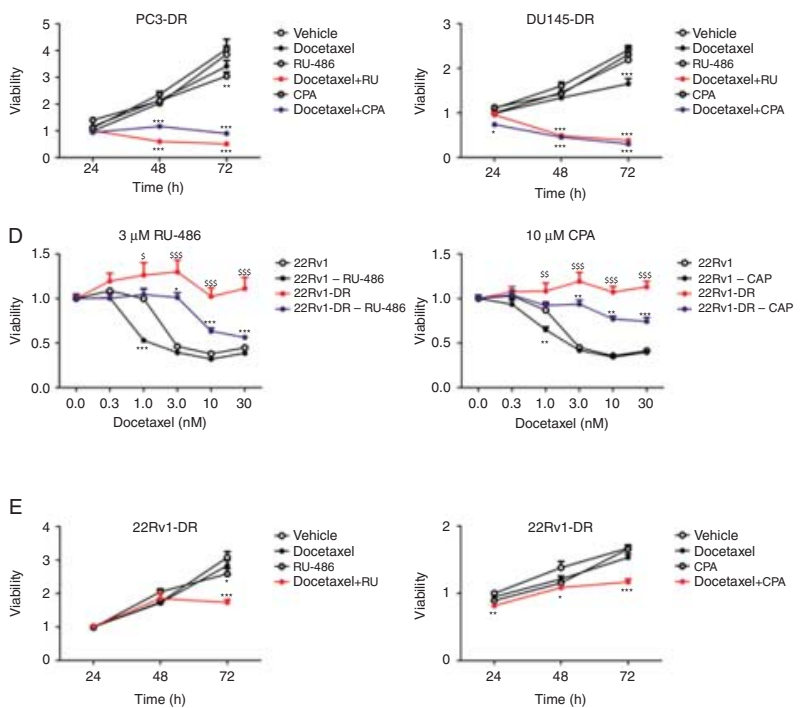

\section{Figure 3}

Therapeutic targeting of the glucocorticoid receptor (GR) resensitizes docetaxel-resistant cell lines to docetaxel. (A) GR antagonism with RU-486 or CPA resensitizes PC3-DR cells for docetaxel treatment after $72 \mathrm{~h}$ of treatment. ${ }^{*} P<0.05$ vs vehicle; ${ }^{*} P P<0.01$ vs vehicle; and $* * * P<0.001$ vs vehicle. (B) Dose-dependent (72 h) and (C) time-dependent (30 nM) antitumor effect of docetaxel upon simultaneous treatment with $3 \mu \mathrm{M}$ RU-486/10 $\mu \mathrm{M}$ CPA and docetaxel in PC3-(DR) and DU145-(DR) cells. ${ }^{\$} P<0.05$ vs parental; ${ }^{\$ \$} P<0.01$ vs parental; ${ }^{\$ \$} P<0.001$ vs parental; $* * P<0.01$ vs docetaxel-resistant line; and $* * * P<0.001$ vs

\section{GR antagonism downregulates antiapoptotic Bcl-2 and $\mathrm{BCl}-\mathbf{x L}$ proteins}

To further elucidate the mechanism of cell death observed above, we performed an Annexin V/PI analysis. Treatment of docetaxel-resistant cells with $3 \mu \mathrm{M}$ RU-486 and $30 \mathrm{nM}$ docetaxel resulted in a decrease of viable cells and an increase in early and late apoptotic cells $(P<0.001$; Fig. 4A). Western blot analysis of antiapoptotic proteins revealed an upregulation of Bcl-2 and Bcl-xL, well-known for their inhibitory role in Bak/Bax-mediated cytochrome $c$ release in the intrinsic apoptotic pathway, in docetaxelresistant cell lines compared with their chemonaive counterparts (Fig. 4B). Interestingly, GR antagonism resulted in decreased expression of antiapoptotic Bcl-xL and Bcl-2 in both docetaxel-resistant cells (Fig. 4B). This suggests that the sensitizing effects of the GR antagonism may be partially mediated via modulation of the Bcl-2/ Bcl-xL axis. To further explore this, a selective antagonist docetaxel-resistant line. (D) GR antagonism with RU-486 or CPA resensitizes AR-positive cell line 22Rv1-DR for docetaxel treatment after $72 \mathrm{~h}$ of treatment. ${ }^{\$} P<0.05$ vs parental; ${ }^{\$ \$} P<0.01$ vs parental; ${ }^{\$ \$} P<0.001$ vs parental; ${ }^{*} P<0.05$ vs docetaxel-resistant line; ${ }^{*} P<0.01$ vs docetaxelresistant line; and $* * * P<0.001$ vs docetaxel-resistant line. (E) Timedependent ( $30 \mathrm{nM})$ antitumor effect of docetaxel upon simultaneous treatment with $3 \mu \mathrm{M}$ RU-486 or $10 \mu \mathrm{M} \mathrm{CPA}$. ${ }^{*} P<0.05$ vs vehicle; ${ }^{*} P<0.01$ vs vehicle; and $* * * P<0.001$ vs vehicle. A full colour version of this figure is available at http://dx.doi.org/10.1530/ERC-15-0343.

for Bcl-2 and Bcl-xL was investigated: ABT-263. Treatment with ABT-263 already induced cell death in PC3-DR and DU145-DR cell lines (Fig. 4C). On top of this, ABT-263 significantly resensitized both docetaxel-resistant cell lines to docetaxel treatment (Fig. 4C). Since this effect with ABT-263 was not as potent as the effect observed with RU-486, other mechanisms in addition to Bcl-xL/Bcl-2 downregulation are presumably involved in the resensitization upon the GR inhibition. This notion is supported by the observation that the sensitivity to docetaxel is enhanced in both docetaxel-resistant cell lines if treated with both RU-486 and ABT-263 compared to RU-486 or ABT-263 alone (Fig. 4C).

\section{Chemotherapy resensitization with RU-486 and CPA cannot be attributed solely to inhibition of P-gp activity}

Previously, an inhibitory effect of RU-486 (Gruol et al. 1994) and CPA (Frohlich et al. 2004) on P-gp activity was

Published by Bioscientifica Ltd 

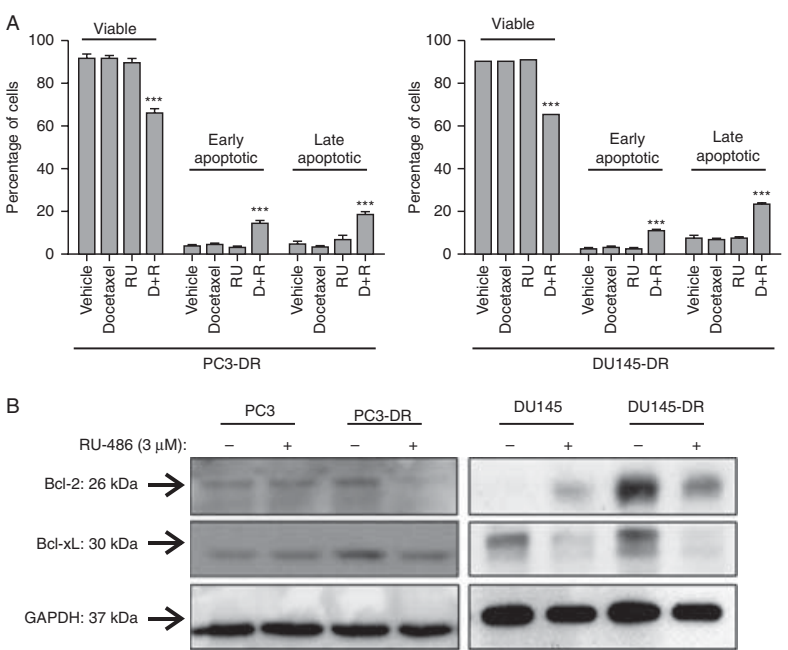

Figure 4

Glucocorticoid receptor (GR) antagonism downregulates the expression of antiapoptotic $\mathrm{BCl}-2$ and $\mathrm{BCl}-\mathrm{xL}$ proteins. (A) Docetaxel-resistant cells undergo apoptosis upon treatment with RU-486 $(3 \mu \mathrm{M})$ and docetaxel $(30 \mathrm{nM}) . * * * P<0.001$ vs vehicle. (B) $\mathrm{BCl}-2$ and $\mathrm{BCl}-\mathrm{XL}$ are upregulated in docetaxel-resistant cell lines. Treatment with RU-486 $(3 \mu \mathrm{M})$ reverses the

described, which could potentially underlie the observed resensitization with the GR antagonists as both PC3-DR and DU145-DR display enhanced P-gp expression (Fig. 5A). To address this, we examined the so called side population, a population of stem-like tumor cells with
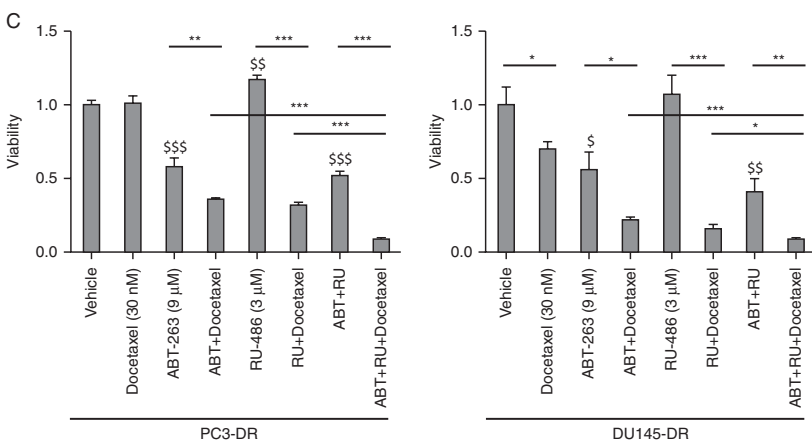

elevated expression of $\mathrm{BCl}-2$ and $\mathrm{BCl}-\mathrm{xL}$ in docetaxel-resistant prostate cancer cells. (C) Co-incubation with an antagonist for $\mathrm{BCl}-2$ and $\mathrm{BCl}-\mathrm{xL}, \mathrm{ABT}$ $263(9 \mu \mathrm{M})$, sensitizes PC3-DR and DU145-DR cells to docetaxel treatment. ${ }^{\star} P<0.05 ;{ }^{* *} P<0.01 ; * * * P<0.001 ;{ }^{\$} P<0.05$ vs vehicle; ${ }^{\$} P<0.01$ vs vehicle; and ${ }^{\$ \$} P<0.001$ vs vehicle.

high P-gp activity leading to the exclusion of P-gp substrate Hoechst. This revealed an enhanced P-gp activity in both docetaxel-resistant cell lines compared to their parental counterparts (Fig. 5B). As expected, RU-486 and CPA display an inhibitory effect on P-gp activity (Fig. 5C).
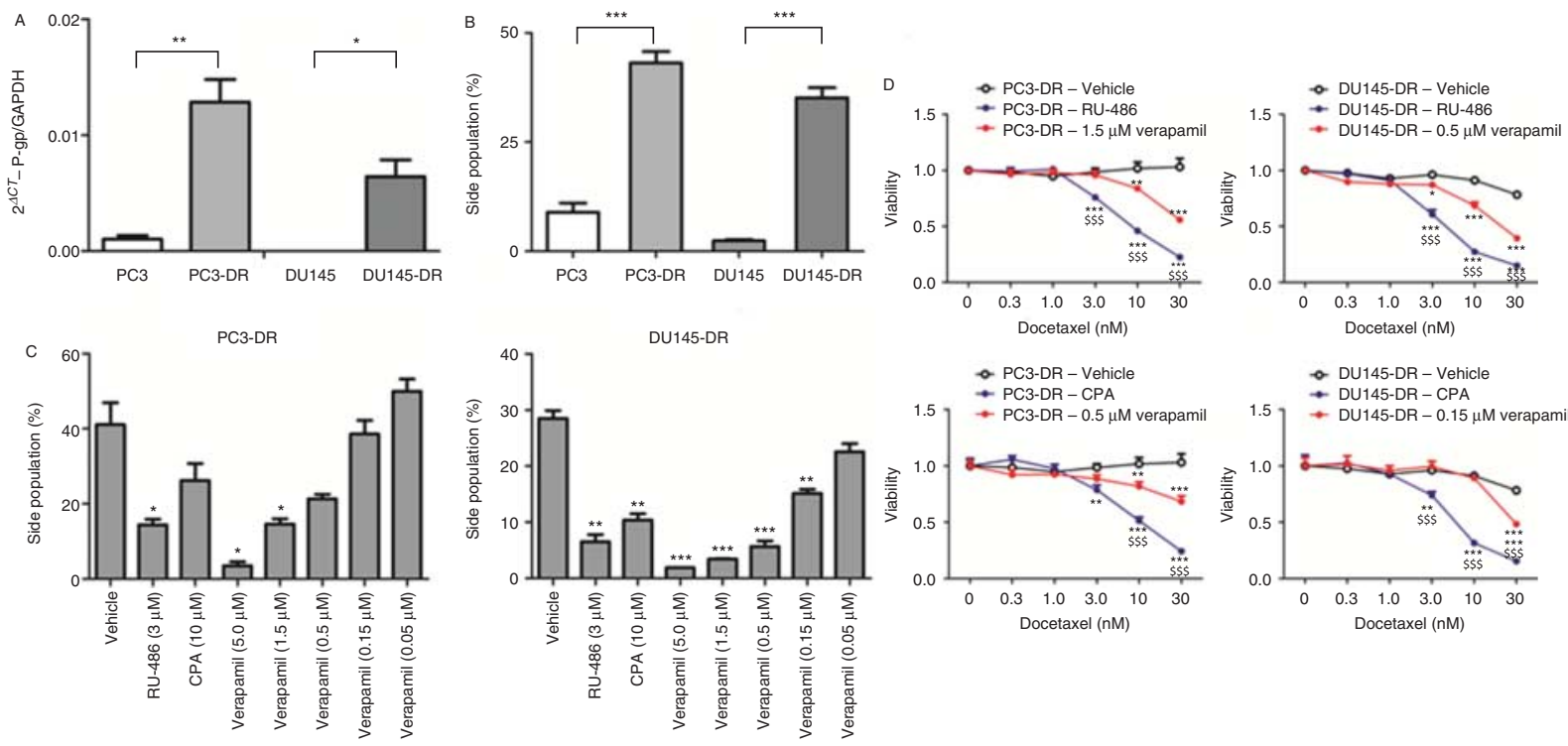

Figure 5

RU-486 and CPA outperform verapamil at dosages with similar P-glycoprotein (P-gp) inhibitory action. (A) P-gp mRNA expression and (B) basal activity in chemo-resistant and sensitive prostate cancer cells. $* P<0.05 ; * * P<0.01$; and $* * * P<0.001$. (C) Head-to-head comparison of the GR antagonists and verapamil on $\mathrm{P}$-gp activity. ${ }^{\star} P<0.05$ vs vehicle;
$* * P<0.01$ vs vehicle; and $* * * P<0.001$ vs vehicle. (D) Head-to-head comparison of the GR antagonists and verapamil on cell viability. ${ }^{\star} P<0.05$ vs vehicle; ${ }^{* *} P<0.01$ vs vehicle; $* * * P<0.001$ vs vehicle; and ${ }^{\$ \$} P<0.001$ vs verapamil. A full colour version of this figure is available at http://dx.doi.org/10.1530/ERC-15-0343.

Published by Bioscientifica Ltd. 
To dissect the resensitizing activities of RU-486 and CPA, we compared their resensitizing capacity to verapamil, a known P-gp inhibitor. Verapamil dosages with equal P-gp inhibitory activity as RU-486 $(1.5 \mu \mathrm{M}$ in PC3-DR and $0.5 \mu \mathrm{M}$ in DU145-DR) and CPA $(0.5 \mu \mathrm{M}$ in PC3-DR; $0.15 \mu \mathrm{M}$ in DU145-DR) (Fig. 5C) were compared headto-head in a viability assay. This revealed a significantly stronger sensitization capacity of both RU-486 and CPA compared to the corresponding verapamil dosages (Fig. 5D), suggesting that a significant proportion of sensitization is indeed mediated via direct inhibition of the GR rather than via P-gp.

\section{Discussion}

In this study, we describe a key role of the GR in PCa docetaxel resistance. We show that the GR is overexpressed in clinical PCa specimens treated with neoadjuvant docetaxel, as well as in docetaxel-resistant PCa cell lines in vitro. While untreated PCa specimens only display the modest GR levels (Yemelyanov et al. 2007, Szmulewitz et al. 2012), androgen ablation therapy or chemotherapy result in upregulation and nuclear localization of the GR (Szmulewitz et al. 2012, Yemelyanov et al. 2012), suggesting the functional involvement of the GR in PCa therapy resistance. Our data fully support this notion and prompted us to further investigate the GR as a therapeutic target in docetaxel-resistant PCa.

Our study reveals a strong resensitizing effect to docetaxel in both AR-negative and AR-positive cell lines upon treatment with the GR antagonists (at dosages that fully antagonize DEX-induced expression of the GR-target genes), suggesting functional involvement of the GR in mediating clinical docetaxel resistance in human PCa. This is supported by recent studies describing the ability of the GR antagonist RU-486 to potentiate the antitumor efficacy of chemotherapeutics in triple-negative breast cancer (paclitaxel; Skor et al. 2013) and cervical cancer (cisplatin; Jurado et al. 2009). Conversely, stimulation of the GR activity by GR exposure (Herr et al. 2003) or stress induction (Reeder et al. 2015) confers resistance to chemotherapeutics, supporting the notion of the GR involvement in chemotherapy resistance.

A range of mechanisms underlying docetaxel resistance have been described including: upregulation of antiapoptotic proteins (Yoshino et al. 2006), overexpression of ABC transporters (Sanchez et al. 2009), aberrant activation of NF- $\mathrm{BB}$ (O'Neill et al. 2011), alterations in $\beta$-tubulin isotypes (Galletti et al. 2007), and expression of AR-V7 (Thadani-Mulero et al. 2014). GCs were shown to contribute to chemotherapy resistance via upregulation of antiapoptotic proteins (Herr et al. 2007). As such, GR-target gene GILZ was shown to induce Bcl-xL expression thereby protecting cardiomyocytes for doxorubicin cytotoxicity (Aguilar et al. 2014). In contrast to hematological malignancies, where GCs may reduce Bcl$\mathrm{xL}$ expression thereby favoring apoptosis (Laane et al. 2007), in PCa it was shown that GCs upregulate Bcl-xL resulting in resistance to apoptosis-inducers (Petrella et al. 2006). We confirmed the upregulation of Bcl-xL in our docetaxel-resistant PCa cells, in line with a previous study (O'Neill et al. 2011), and show here that GR antagonism leads to a reduction in Bcl-xL expression, providing a potential mechanistic explanation for the restored sensitivity to docetaxel in resistant PCa cells.

Yet, we cannot fully attribute the resensitizing capacity of the GR antagonists to the GR, as both steroidal drugs (RU-486 and CPA) were reported to directly inhibit P-gp function (Gruol et al. 1994, Frohlich et al. 2004). In our studies, we compared RU-486 and CPA head-to-head to known P-gp inhibitor verapamil. Interestingly, at dosages with equal P-gp inhibition, both RU-486 and CPA outperformed verapamil, suggesting that mechanisms other than P-gp inhibition are responsible, i.e., the GR pathway. It is unclear, however, if an inhibitory effect on P-gp function underlies the sensitizing effects of RU-486 on paclitaxel and cisplatin reported in literature (Jurado et al. 2009, Skor et al. 2013). P-gp was shown to be expressed in the cell lines used (MDA-MB231; Zhang et al. 2014) and HeLa (Al-Abd et al. 2011) respectively) but the issue is not discussed in these reports. Besides P-gp, GR antagonists were also described to affect progesterone receptor (PR) activity (Honer et al. 2003), although the effects of the GR antagonists on docetaxel sensitivity seem to be PR-independent since we observe sensitizing effects in both PR-positive (DU145 and 22Rv1; Lau et al. 2000, Hartel et al. 2004) and PR-negative cell lines (PC3; Lau et al. 2000).

DEX is routinely used in the treatment of patients with advanced $\mathrm{PCa}$, although it actually may contribute to resistance to therapy. Indeed, the functional involvement of the GR in resistance to anti-AR therapy (i.e. enzalutamide) was demonstrated (Arora et al. 2013, Isikbay et al. 2014). Enhanced GR expression was observed in enzalutamide-resistant tumors in vivo and in tumor biopsies from enzalutamide-pretreated PCa patients (Arora et al. 2013). AR was shown to directly repress GR expression in PCa via a negative AR response element in the GR-promoter (Xie et al. 2015). It was proposed that GR is able to take over AR function due to a significant overlap in transcriptome.

Published by Bioscientifica Ltd. 
As a consequence, stimulation of the GR activity can rescue cells from enzalutamide-induced cell death (Arora et al. 2013).

We now demonstrate that the GR is upregulated in PCa tumors of patients treated with docetaxel. As GCs are frequently administered in combination with docetaxel, GC usage may counteract the antitumor efficacy of this chemotherapeutic agent. Alternatively, GC administration prior to treatment with chemotherapeutics agents may actually increase sensitivity to chemotherapeutics due to homologous downregulation of the GR (Rosewicz et al. 1988). Hence, phased timing (i.e. precise treatment sequencing) of GCs in combination with other treatment options (chemotherapy or anti-AR therapy) should be carefully considered. Reassuringly, a recent meta-analysis on the usage of GC prednisone showed no difference in overall survival in prednisone vs nonprednisone treated patients (Morgan et al. 2014).

Based on our preclinical results, combinational treatment with docetaxel and GR antagonists may be a promising therapeutic approach in docetaxel-resistant disease. Currently, CRPC patients that progress on docetaxel are routinely treated with AR- or AR-axis targeting drugs (i.e. abiraterone acetate or enzalutamide; de Bono et al. 2011, Scher et al. 2012). Not all patients, however, respond to therapeutic targeting of the AR-axis, in particular those with AR-V7-expressing tumors (Antonarakis et al. 2014). Although the clinical importance of AR-V7 in resistance to docetaxel is not confirmed (Antonarakis et al. 2015, Onstenk et al. 2015), preclinical studies do suggest that expression of AR-V7 promotes resistance to taxane-based chemotherapeutics (ThadaniMulero et al. 2014, Zhang et al. 2015). We now show that combined GR antagonism and docetaxel treatment may also be effective in AR-V7-expressing, docetaxel-resistant PCa cells. Our study also reveals enhanced GR levels as a result of docetaxel treatment, and augmented GR may significantly undermine the efficacy of AR-targeting agents in patients that progress on docetaxel treatment (Arora et al. 2013). Based on this, GR antagonism may also be useful in combination with AR-targeting drugs. A phase I/II clinical study assessing combined treatment with enzalutamide and RU-486 is currently ongoing (NCT02012296) to identify the recommended dose of RU-486 and to monitor adverse effects and antitumor activity of this drug combination. It is interesting to note that RU-486 (as a mono treatment) was already assessed in a phase II clinical trial in CRPC patients in which a treatment schedule of $200 \mathrm{mg} /$ day orally was very well tolerated (Taplin et al. 2008). In addition, other parameters influenced by GR activity, e.g., bone mineral density, were not influenced upon RU-486 treatment (Kettel et al. 1996). Taken together, the use of the GR inhibitors in CRPC patients is well tolerated and preclinical studies endorse further development towards clinical translation.

In summary, we believe that the clinical use of the GR antagonists could be beneficial in advanced PCa patients, as GR is often overexpressed. Combination treatment of the GR antagonists with docetaxel is worthwhile pursuing in order to enhance the antitumor efficacy of docetaxel in the treatment of patients with chemotherapy resistant PCa.

\section{Supplementary data}

This is linked to the online version of the paper at http://dx.doi.org/10.1530/ ERC-15-0343.

Declaration of interest

The authors declare that there is no conflict of interest that could be perceived as prejudicing the impartiality of the research reported.

\section{Funding}

J Kroon is supported by NanoNextNL Drug Delivery programme 03D.01. $M$ Puhr is supported by an Austrian Science Fund (FWF) grant number P25639-B19. J T Buijs is supported by the Netherlands Organisation for Scientific Research (NWO, VENI-grant-916.131.10). G van der Horst is supported by the Dutch Cancer Society (KWF, UL-2011-4030).

\section{Author contribution statement}

J Kroon designed, carried out and analyzed the in vitro experiments and wrote the manuscript. M Puhr performed and analyzed the immunohistochemical study with the TMA and established the PC3-DR and DU145-DR cell lines. J T Buijs, G van der Horst, and D M Hemmer contributed to the data acquisition and interpretation. K A Marijt designed and cloned the CRISPR/CAS9 plasmids. M S Hwang, M Masood, and S Grimm carried out the western blot analysis of antiapoptotic proteins. J M Metselaar, G Storm, O C Meijer, and Z Culig provided invaluable intellectual input on the study design and concepts. G van der Pluijm supervised J Kroon, provided intellectual input and helped writing the manuscript. All co-authors improved the manuscript and approved its final version.

\section{Acknowledgements}

The authors thank Hetty Sips for technical assistance and Sander Kooijman for critical reading of the manuscript. We thank Prof. Dr William Watson (University College Dublin) for providing the 22Rv1 parental and 22Rv1 docetaxel-resistant cell lines.

\section{References}

Aguilar D, Strom J \& Chen QM 2014 Glucocorticoid induced leucine zipper inhibits apoptosis of cardiomyocytes by doxorubicin. Toxicology and Applied Pharmacology 276 55-62. (doi:10.1016/j.taap.2014.01.013)

Published by Bioscientifica Ltd. 
Al-Abd AM, Mahmoud AM, El-Sherbiny GA, El-Moselhy MA, Nofal SM, El-Latif HA, El-Eraky WI \& El-Shemy HA 2011 Resveratrol enhances the cytotoxic profile of docetaxel and doxorubicin in solid tumour cell lines in vitro. Cell Proliferation 44 591-601. (doi:10.1111/j.1365-2184. 2011.00783.x)

Antonarakis ES, Lu C, Wang H, Luber B, Nakazawa M, Roeser JC, Chen Y, Mohammad TA, Chen Y, Fedor HL et al. 2014 AR-V7 and resistance to enzalutamide and abiraterone in prostate cancer. New England Journal of Medicine 371 1028-1038. (doi:10.1056/NEJMoa1315815)

Antonarakis ES, Lu C, Luber B, Wang H, Chen Y, Nakazawa M, Nadal R, Paller CJ, Denmeade SR, Carducci MA et al. 2015 Androgen receptor splice variant 7 and efficacy of taxane chemotherapy in patients with metastatic castration-resistant prostate cancer. JAMA Oncology 1 582-591. (doi:10.1001/jamaoncol.2015.1341)

Arora VK, Schenkein E, Murali R, Subudhi SK, Wongvipat J, Balbas MD, Shah N, Cai L, Efstathiou E, Logothetis C et al. 2013 Glucocorticoid receptor confers resistance to antiandrogens by bypassing androgen receptor blockade. Cell 155 1309-1322. (doi:10.1016/j.cell.2013. 11.012)

de Bono JS, Logothetis CJ, Molina A, Fizazi K, North S, Chu L, Chi KN, Jones RJ, Goodman OB Jr, Saad F et al. 2011 Abiraterone and increased survival in metastatic prostate cancer. New England Journal of Medicine 364 1995-2005. (doi:10.1056/NEJMoa1014618)

Frohlich M, Albermann N, Sauer A, Walter-Sack I, Haefeli WE \& Weiss J 2004 In vitro and ex vivo evidence for modulation of P-glycoprotein activity by progestins. Biochemical Pharmacology 68 2409-2416. (doi:10.1016/j.bcp.2004.08.026)

Galletti E, Magnani M, Renzulli ML \& Botta M 2007 Paclitaxel and docetaxel resistance: molecular mechanisms and development of new generation taxanes. ChemMedChem 2 920-942. (doi:10.1002/cmdc. 200600308)

Golebiewska A, Brons NH, Bjerkvig R \& Niclou SP 2011 Critical appraisal of the side population assay in stem cell and cancer stem cell research. Cell Stem Cell 8 136-147. (doi:10.1016/j.stem.2011.01.007)

Gruol DJ, Zee MC, Trotter J \& Bourgeois S 1994 Reversal of multidrug resistance by RU 486. Cancer Research $\mathbf{5 4}$ 3088-3091.

Hartel A, Didier A, Ulbrich SE, Wierer M \& Meyer HH 2004 Characterisation of steroid receptor expression in the human prostate carcinoma cell line 22RV1 and quantification of androgen effects on mRNA regulation of prostate-specific genes. Journal of Steroid Biochemistry and Molecular Biology 92 187-197. (doi:10.1016/j.jsbmb.2004.07.004)

Herr I, Ucur E, Herzer K, Okouoyo S, Ridder R, Krammer PH, von Knebel Doeberitz M \& Debatin KM 2003 Glucocorticoid cotreatment induces apoptosis resistance toward cancer therapy in carcinomas. Cancer Research 63 3112-3120.

Herr I, Gassler N, Friess H \& Buchler MW 2007 Regulation of differential pro- and anti-apoptotic signaling by glucocorticoids. Apoptosis $\mathbf{1 2}$ 271-291. (doi:10.1007/s10495-006-0624-5)

Honer C, Nam K, Fink C, Marshall P, Ksander G, Chatelain RE, Cornell W, Steele R, Schweitzer R \& Schumacher C 2003 Glucocorticoid receptor antagonism by cyproterone acetate and RU486. Molecular Pharmacology 63 1012-1020. (doi:10.1124/mol.63.5.1012)

Isikbay M, Otto K, Kregel S, Kach J, Cai Y, Vander Griend DJ, Conzen SD \& Szmulewitz RZ 2014 Glucocorticoid receptor activity contributes to resistance to androgen-targeted therapy in prostate cancer. Hormones \& Cancer 5 72-89. (doi:10.1007/s12672-014-0173-2)

Jurado R, Lopez-Flores A, Alvarez A \& Garcia-Lopez P 2009 Cisplatin cytotoxicity is increased by mifepristone in cervical carcinoma: an in vitro and in vivo study. Oncology Reports 22 1237-1245.

Kettel LM, Murphy AA, Morales AJ, Ulmann A, Baulieu EE \& Yen SS 1996 Treatment of endometriosis with the antiprogesterone mifepristone (RU486). Fertility and Sterility 65 23-28.

Kroon J, Buijs JT, van der Horst G, Cheung H, van der Mark M, van Bloois L, Rizzo LY, Lammers T, Pelger RC, Storm G et al. 2015 Liposomal delivery of dexamethasone attenuates prostate cancer bone metastatic tumor growth in vivo. Prostate 75 815-824. (doi:10.1002/pros.22963)
Laane E, Panaretakis T, Pokrovskaja K, Buentke E, Corcoran M, Soderhall S, Heyman M, Mazur J, Zhivotovsky B, Porwit A et al. 2007 Dexamethasone-induced apoptosis in acute lymphoblastic leukemia involves differential regulation of Bcl-2 family members. Haematologia $\mathbf{9 2}$ 1460-1469. (doi:10.3324/haematol.10543)

Lau KM, LaSpina M, Long J \& Ho SM 2000 Expression of estrogen receptor (ER)- $\alpha$ and ER- $\beta$ in normal and malignant prostatic epithelial cells: regulation by methylation and involvement in growth regulation. Cancer Research 60 3175-3182.

Lewis-Tuffin LJ \& Cidlowski JA 2006 The physiology of human glucocorticoid receptor $\beta$ (hGR $\beta$ ) and glucocorticoid resistance. Annals of the New York Academy of Sciences 1069 1-9. (doi:10.1196/ annals.1351.001)

Madan RA, Pal SK, Sartor O \& Dahut WL 2011 Overcoming chemotherapy resistance in prostate cancer. Clinical Cancer Research 17 3892-3902. (doi:10.1158/1078-0432.CCR-10-2654)

Montgomery B, Cheng HH, Drechsler J \& Mostaghel EA 2014 Glucocorticoids and prostate cancer treatment: friend or foe? Asian Journal of Andrology 16 354-358. (doi:10.4103/1008-682X.125392)

Morgan CJ, Oh WK, Naik G, Galsky MD \& Sonpavde G 2014 Impact of prednisone on toxicities and survival in metastatic castration-resistant prostate cancer: a systematic review and meta-analysis of randomized clinical trials. Critical Reviews in Oncology/Hematology 90 253-261. (doi:10.1016/j.critrevonc.2013.12.001)

O'Neill AJ, Prencipe M, Dowling C, Fan Y, Mulrane L, Gallagher WM, O'Connor D, O'Connor R, Devery A, Corcoran C et al. 2011 Characterisation and manipulation of docetaxel resistant prostate cancer cell lines. Molecular Cancer 10 126. (doi:10.1186/1476-459810-126)

Onstenk W, Sieuwerts AM, Kraan J, Van M, Nieuweboer AJ, Mathijssen RH, Hamberg P, Meulenbeld HJ, Laere B, Dirix LY et al. 2015 Efficacy of cabazitaxel in castration-resistant prostate cancer is independent of the presence of AR-V7 in circulating tumor cells. European Urology 68 939-945. (doi:10.1016/j.eururo.2015.07.007)

Petrella A, Ercolino SF, Festa M, Gentilella A, Tosco A, Conzen SD \& Parente L 2006 Dexamethasone inhibits TRAIL-induced apoptosis of thyroid cancer cells via Bcl-xL induction. European Journal of Cancer 42 3287-3293. (doi:10.1016/j.ejca.2006.07.018)

Puhr M, Hoefer J, Schafer G, Erb HH, Oh SJ, Klocker H, Heidegger I, Neuwirt H \& Culig Z 2012 Epithelial-to-mesenchymal transition leads to docetaxel resistance in prostate cancer and is mediated by reduced expression of miR-200c and miR-205. American Journal of Pathology 181 2188-2201. (doi:10.1016/j.ajpath.2012.08.011)

Puhr M, Hoefer J, Neuwirt H, Eder IE, Kern J, Schafer G, Geley S, Heidegger I, Klocker H \& Culig Z 2014 PIAS1 is a crucial factor for prostate cancer cell survival and a valid target in docetaxel resistant cells. Oncotarget 5 12043-12056. (doi:10.18632/oncotarget.2658)

Reeder A, Attar M, Nazario L, Bathula C, Zhang A, Hochbaum D, Roy E, Cooper KL, Oesterreich S, Davidson NE et al. 2015 Stress hormones reduce the efficacy of paclitaxel in triple negative breast cancer through induction of DNA damage. British Journal of Cancer 112 1461-1470. (doi:10.1038/bjc.2015.133)

Rosewicz S, McDonald AR, Maddux BA, Goldfine ID, Miesfeld RL \& Logsdon CD 1988 Mechanism of glucocorticoid receptor downregulation by glucocorticoids. Journal of Biological Chemistry $\mathbf{2 6 3}$ 2581-2584.

Sanchez C, Mendoza P, Contreras HR, Vergara J, McCubrey JA, Huidobro C \& Castellon EA 2009 Expression of multidrug resistance proteins in prostate cancer is related with cell sensitivity to chemotherapeutic drugs. Prostate 69 1448-1459. (doi:10.1002/pros.20991)

Scher HI, Fizazi K, Saad F, Taplin ME, Sternberg CN, Miller K, de Wit R, Mulders P, Chi KN, Shore ND et al. 2012 Increased survival with enzalutamide in prostate cancer after chemotherapy. New England Journal of Medicine 367 1187-1197. (doi:10.1056/NEJMoa1207506)

Shiota M, Yokomizo A, Takeuchi A, Imada K, Kashiwagi E, Song Y, Inokuchi J, Tatsugami K, Uchiumi T \& Naito S 2014 Inhibition of

Published by Bioscientifica Ltd 
protein kinase C/Twist1 signaling augments anticancer effects of androgen deprivation and enzalutamide in prostate cancer. Clinical Cancer Research 20 951-961. (doi:10.1158/1078-0432.CCR-13-1809)

Skor MN, Wonder EL, Kocherginsky M, Goyal A, Hall BA, Cai Y \& Conzen SD 2013 Glucocorticoid receptor antagonism as a novel therapy for triple-negative breast cancer. Clinical Cancer Research 19 6163-6172. (doi:10.1158/1078-0432.CCR-12-3826)

van Soest RJ, de Morree ES, Kweldam CF, de Ridder CM, Wiemer EA, Mathijssen RH, de Wit R \& van Weerden WM 2014 Targeting the androgen receptor confers in vivo cross-resistance between enzalutamide and docetaxel, but not cabazitaxel, in castration-resistant prostate cancer. European Urology 67 981-985. (doi:10.1016/j.eururo.2014.11.033)

Szmulewitz RZ, Chung E, Al-Ahmadie H, Daniel S, Kocherginsky M, Razmaria A, Zagaja GP, Brendler CB, Stadler WM \& Conzen SD 2012 Serum/glucocorticoid-regulated kinase 1 expression in primary human prostate cancers. Prostate 72 157-164. (doi:10.1002/pros.21416)

Tannock IF, de Wit R, Berry WR, Horti J, Pluzanska A, Chi KN, Oudard S, Theodore C, James ND, Turesson I et al. 2004 Docetaxel plus prednisone or mitoxantrone plus prednisone for advanced prostate cancer. New England Journal of Medicine 351 1502-1512. (doi:10.1056/ NEJMoa040720)

Taplin ME, Manola J, Oh WK, Kantoff PW, Bubley GJ, Smith M, Barb D, Mantzoros C, Gelmann EP \& Balk SP 2008 A phase II study of mifepristone (RU-486) in castration-resistant prostate cancer, with a correlative assessment of androgen-related hormones. BJU International 101 1084-1089. (doi:10.1111/j.1464-410X.2008.07509.x)

Thadani-Mulero M, Portella L, Sun S, Sung M, Matov A, Vessella RL, Corey E, Nanus DM, Plymate SR \& Giannakakou P 2014 Androgen receptor splice variants determine taxane sensitivity in prostate cancer. Cancer Research 74 2270-2282. (doi:10.1158/0008-5472.CAN-13-2876)

Venkitaraman R, Thomas K, Huddart RA, Horwich A, Dearnaley DP \& Parker CC 2008 Efficacy of low-dose dexamethasone in castrationrefractory prostate cancer. BJU International $101440-443$.
Xie N, Cheng H, Lin D, Liu L, Yang O, Jia L, Fazli L, Gleave ME, Wang Y, Rennie P et al. 2015 The expression of glucocorticoid receptor is negatively regulated by active androgen receptor signaling in prostate tumors. International Journal of Cancer 136 E27-E38. (doi:10.1002/ijc. 29147)

Yemelyanov A, Czwornog J, Chebotaev D, Karseladze A, Kulevitch E, Yang X \& Budunova I 2007 Tumor suppressor activity of glucocorticoid receptor in the prostate. Oncogene 26 1885-1896. (doi:10.1038/sj.onc. 1209991)

Yemelyanov A, Bhalla P, Yang X, Ugolkov A, Iwadate K, Karseladze A \& Budunova I 2012 Differential targeting of androgen and glucocorticoid receptors induces ER stress and apoptosis in prostate cancer cells: a novel therapeutic modality. Cell Cycle 11 395-406. (doi:10.4161/cc.11. 2.18945)

Yoshino T, Shiina H, Urakami S, Kikuno N, Yoneda T, Shigeno K \& Igawa M $2006 \mathrm{Bcl}-2$ expression as a predictive marker of hormonerefractory prostate cancer treated with taxane-based chemotherapy. Clinical Cancer Research 12 6116-6124. (doi:10.1158/1078-0432. CCR-06-0147)

Zhang C, Wenger T, Mattern J, Ilea S, Frey C, Gutwein P, Altevogt P, Bodenmuller W, Gassler N, Schnabel PA et al. 2007 Clinical and mechanistic aspects of glucocorticoid-induced chemotherapy resistance in the majority of solid tumors. Cancer Biology \& Therapy 6 278-287. (doi:10.4161/cbt.6.2.3652)

Zhang Q, Wang J, He H, Liu H, Yan X \& Zou K 2014 Trametenolic acid B reverses multidrug resistance in breast cancer cells through regulating the expression level of P-glycoprotein. Phytotherapy Research $\mathbf{2 8}$ 1037-1044. (doi:10.1002/ptr.5089)

Zhang G, Liu X, Li J, Ledet E, Alvarez X, Qi Y, Fu X, Sartor O, Dong Y \& Zhang H 2015 Androgen receptor splice variants circumvent AR blockade by microtubule-targeting agents. Oncotarget 6 23358-23371. (doi:10.18632/oncotarget.4396)

Received in final form 16 October 2015

Accepted 19 October 2015

Made available online as an Accepted Preprint

19 October 2015 (c) 2016 The authors Printed in Great Britain
Published by Bioscientifica Ltd. 